\title{
Przygotowanie nadawy do procesu granulacji nawarstwiającej w młynie wibracyjnym
}

\author{
Paweł Tomach (D), Jan Sidor \\ AGH Akademia Górniczo-Hutnicza, Wydział Inżynierii Mechanicznej i Robotyki, Kraków
}

\begin{abstract}
Streszczenie: Nawóz mineralny o wysokiej aktywności powinien mieć przed granulacją uziarnienie o zawartości klasy ziarnowej $0-10 \mu \mathrm{m}$ powyżej $70 \%$. Nadawą do granulacji były dwa rodzaje wapienia oraz kreda. Nadawę przygotowano przez mielenie w laboratoryjnym młynie wibracyjnym o działaniu okresowym i przy niskiej częstotliwości drgań - $14 \mathrm{~Hz}$. Proces mielenia przeprowadzano na sucho, bez udziału aktywatora, uzyskując zmielone materiały o zawartości klasy ziarnowej 0-10 $\mu \mathrm{m}$ - dla wapieni w zakresie $84-95 \%$, a dla kredy - 87\%. Wyniki badań wskazują, że młyn wibracyjny można zastosować do przygotowania nadawy do granulacji bezciśnieniowej, w celu wytwarzania nawozów mineralnych o wysokiej aktywności.
\end{abstract}

Słowa kluczowe: granulacja nawozu, młyn wibracyjny, mielenie wibracyjne

\section{THE USE OF A VIBRATORY MILL FOR FEED PREPARATION FOR THE LAYERED GRANULATION PROCESS}

\begin{abstract}
Mineral fertilizer of high activity should contain (before granulation) grain class 0-10 microns in amount greater than $70 \%$. Feed for granulation were two types of limestone and chalk. The feed was prepared by milling in a laboratory vibratory mill batchwise and with low vibration frequency $14 \mathrm{~Hz}$. The milling process was performed dry, without the activator, to obtain grain class 0-10 microns: for the limestone in the range from 84 to $95 \%$, and $87 \%$ for the chalk. The results indicate that vibratory mills can be used to prepare feed for non-pressurized granulation that is for preparation of granulated mineral fertilizers with high activity.
\end{abstract}

Keywords: fertilizer granulation, vibratory mill, vibratory milling

https://doi.org/10.7494/978-83-66727-48-9_12 


\section{Wprowadzenie}

Granulacja bezciśnieniowa stosowana jest w procesach wytwarzania nawozów mineralnych, farmaceutyków, wielu innych granulowanych produktów, a także w przygotowaniu do zagospodarowania drobno uziarnionych odpadów przemysłowych. Problematyka granulacji stale się rozwija i stanowi przedmiot wielu prac badawczych (Biń 2012). Drobno uziarnione materiały przed poddaniem granulacji powinny być odpowiednio przygotowane. Często jednym z tych procesów jest proces rozdrabniania, zwłaszcza mielenia (Malinowski i in. 2015), w którym wytwarzane są najdrobniejsze klasy ziarnowe ułatwiające proces granulacji. W wielu przypadkach bez wcześniejszego rozdrobnienia materiału nie można go zgranulować. Proces ten zachodzi najczęściej w młynach grawitacyjnych, nazywanych ze względu na rodzaj mielników młynami kulowymi (Heim 1998, Warych 2014). Najnowsze rozwiązania konstrukcyjne tych młynów i ich parametry technologiczne podane zostały przez Sidora (2013). Młyny te charakteryzuje duży jednostkowy pobór energii, dlatego w wielu technologiach wypierane sa przez młyny o znacznie większych możliwościach technologicznych i mniejszym o ponad połowę poborze energii (Gock i in. 2006), czyli młyny wibracyjne (Andres i in. 2011, Sidor 2005, 2011, Sidor i in. 1997, 2002) i mieszadłowe (Heim 1998, Tamblyn 2009, Rule 2010, Sidor 2013). Znaczącą zaletą tych młynów są niższe koszty inwestycyjne i eksploatacyjne, dlatego też w Katedrze Inżynierii Maszyn i Transportu AGH prowadzone są prace badawcze nad tego typu młynami (Tomach 2017a, 2017b, 2019, 2020). Od wielu lat zauważalny jest wzrost produkcji nawozów granulowanych (Heffer i in. 2014), a od kilku lat znaczący wzrost cen energii elektrycznej - oba te aspekty zdeterminowały podjęcie prac w tej dziedzinie.

W pracy, która ma charakter eksperymentalny i sondażowy, przedstawiono próbę zastosowania młyna wibracyjnego do przygotowania wapieni i kredy jako nadawy do granulacji bezciśnieniowej. Materiały te przewidziano do zastosowania jako nawóz mineralny w formie granulatu.

Możliwość wykorzystania młyna wibracyjnego do bardzo drobnego mielenia surowców mineralnych, czyli przygotowania nadawy do granulacji w granulatorze wibracyjnym, potwierdziły korzystne wyniki badań granulacji sześciu surowców mineralnych (w tym wapieni) zmielonych w młynie wibracyjnym (Sidor i in. 2014).

\section{Cel i metoda badań}

Celem badań było określenie możliwości otrzymania w młynie wibracyjnym, o działaniu okresowym i niskiej częstotliwości drgań, produktu mielenia stanowiącego 
nadawę do procesu granulacji bezciśnieniowej. Badania obejmowały również wyznaczenie parametrów mielenia wibracyjnego w celu otrzymania produktu mielenia o zawartości klasy 0-10 $\mu \mathrm{m}$ minimum $70 \%$ - przy standardowych parametrach młyna oraz w możliwie najkrótszym czasie mielenia.

Do badań przyjęto trzy materiały, to jest: wapień oznaczony symbolem A, kredę oznaczoną symbolem B oraz wapień oznaczony symbolem C. Materiały były w stanie suchym. Ich skład ziarnowy i gęstość nasypową w stanie luźnym podano w tabeli 1.

Tabela 1

Uziarnienie oraz gęstość nasypowa materiałów A, B i C

\begin{tabular}{|c|c|c|c|c|c|c|c|}
\hline \multirow{3}{*}{$\begin{array}{c}\text { Wymiary } \\
\text { oczek } \\
{[\mathrm{mm}]}\end{array}$} & \multirow{3}{*}{$\begin{array}{c}\text { Klasa ziarnowa } \\
{[\mathrm{mm}]}\end{array}$} & \multicolumn{6}{|c|}{ Materiał } \\
\hline & & \multicolumn{2}{|c|}{ Wapień A } & \multicolumn{2}{|c|}{ Kreda B } & \multicolumn{2}{|c|}{ Wapień C } \\
\hline & & $\begin{array}{c}\text { suma } \\
\text { frakcji } \\
{[\%]}\end{array}$ & $\begin{array}{c}\text { przesiew } \\
{[\%]}\end{array}$ & $\begin{array}{c}\text { suma } \\
\text { frakcji } \\
{[\%]}\end{array}$ & $\begin{array}{c}\text { przesiew } \\
{[\%]}\end{array}$ & $\begin{array}{c}\text { suma } \\
\text { frakcji } \\
{[\%]}\end{array}$ & $\begin{array}{c}\text { przesiew } \\
{[\%]}\end{array}$ \\
\hline 10 & $>10$ & 0,00 & 100,00 & 0,00 & 100,00 & 0,00 & 100,00 \\
\hline 8 & $8-10$ & 0,00 & 100,00 & 2,50 & 97,50 & 0,00 & 100,00 \\
\hline 4 & $4-6$ & 0,00 & 100,00 & 43,70 & 56,30 & 0,30 & 99,70 \\
\hline 2 & $2-4$ & 1,19 & 98,81 & 85,20 & 14,80 & 9,10 & 90,90 \\
\hline 1 & $1-2$ & 23,62 & 76,38 & 95,90 & 4,10 & 50,20 & 49,80 \\
\hline 0,5 & $0,50-1,00$ & 48,33 & 51,67 & 98,40 & 1,60 & 72,40 & 27,60 \\
\hline 0,25 & $0,25-0,50$ & 66,08 & 33,92 & 98,90 & 1,10 & 82,40 & 17,60 \\
\hline- & $<0,25$ & 99,70 & 0,30 & 99,40 & 0,60 & 99,60 & 0,40 \\
\hline \multicolumn{2}{|c|}{$\begin{array}{c}\text { Gęstość nasypowa } \\
{\left[\mathrm{kg} / \mathrm{dm}^{3}\right]}\end{array}$} & \multicolumn{2}{|c|}{$1,44 \pm 0,03$} & \multicolumn{2}{|c|}{$1,05 \pm 0,03$} & \multicolumn{2}{|c|}{$1,68 \pm 0,04$} \\
\hline
\end{tabular}

Stanowisko badawcze laboratoryjnego młyna wibracyjnego o działaniu okresowym (schemat budowy i widok) przedstawiono na rysunku 1 (Sidor 2005). Do badań przyjęto komorę o średnicy $210 \mathrm{~mm}$ z wykładziną stalową o pojemności $2,2 \mathrm{dm}^{3}$ (znajdującą się w uchwycie komory - rys. 1a), a jako elementy robocze - kulki stalowe. Taką średnicę komór mają najmniejsze przemysłowe młyny wibracyjne. Młyn ten może być również wyposażony w komory o średnicy 123 mm i $310 \mathrm{~mm}$ oraz komory z wykładziną z tworzywa polimerowego i korundową. Częstotliwość drgań komory wynosiła $14 \mathrm{~Hz}$, a stopień napełnienia komory $70 \%$. 
a)

b)

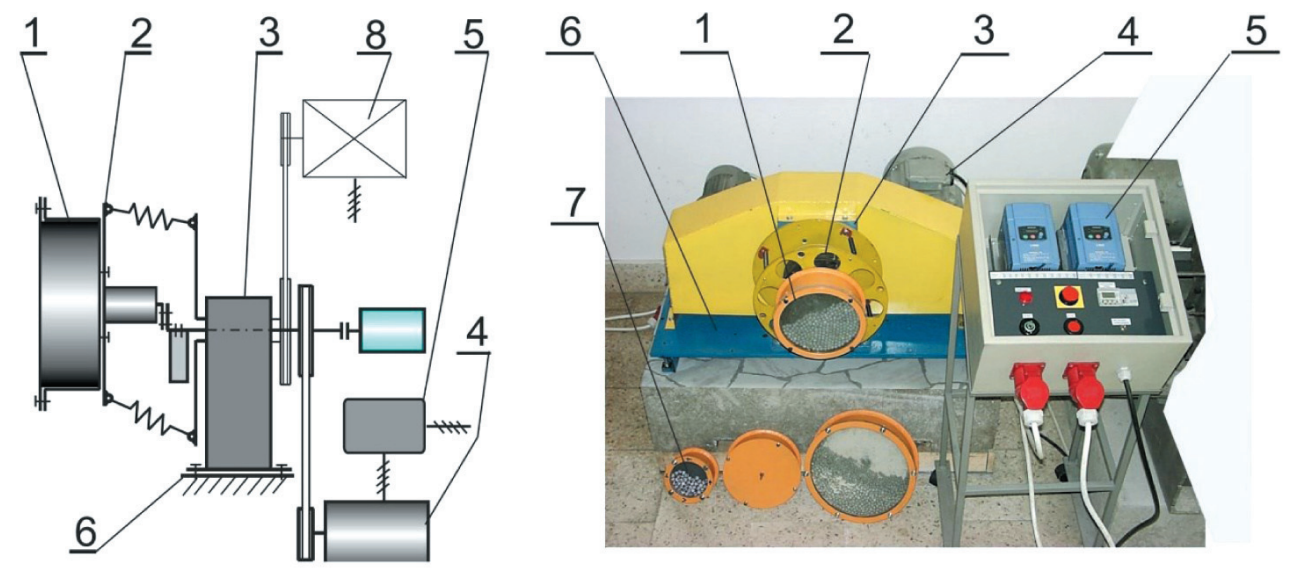

Rys. 1. Stanowisko badawcze laboratoryjnego młyna wibracyjnego: a) schemat; b) widok; 1 - komora, 2 - uchwyt komory, 3 - moduł napędu, 4 - silnik wibratora, 5 - układ sterowania i zasilania, 6 - podstawa, 7 - dodatkowe komory o innych średnicach, 8 - napęd ruchu obrotowego komory (nieużywany w badaniach)

\section{Metodyka, przebieg i wyniki badań}

Sondażowe badania procesu mielenia wibracyjnego wapieni i kredy przeprowadzono zgodnie z przyjętą metodą. W badaniach nie stosowano aktywatorów, czyli środków ułatwiających mielenie. Każdą z prób mielenia powtarzano dwukrotnie, a końcowy wynik stanowi średnia arytmetyczną z dwóch prób oraz dwóch oznaczeń uziarnienia. Uziarnienie zmielonych próbek oznaczano metodą dyfraktometryczną - granulometrem laserowym LAU-15. Próbki dyspergowano alkoholem izopropylowym.

Dla każdego z materiałów wyznaczano kinetykę procesu mielenia, czyli wpływ czasu mielenia na wybrane parametry uziarnienia, w szczególności na zawartość klasy ziarnowej 0-10 $\mu \mathrm{m}$ oraz wymiar ziarna $\mathrm{d}_{90}$. Proces mielenia każdego materiału kontynuowano nawet po otrzymaniu wymaganej zawartości tej klasy, to jest 70\%, aby ocenić możliwości technologiczne młyna. Wyniki badań zamieszczono na rysunkach 2 i 3.

W tabeli 2 zestawiono wyniki badań uziarnienia próbek spełniających wymóg technologiczny uziarnienia wraz z podaniem czasu ich mielenia. Na rysunkach 4-6 zamieszczono kompletne składy ziarnowe tych próbek. Rysunki te stanowią wynik generowany przez oprogramowanie granulometru LAU, gdzie kolorem filetowym przedstawiona jest krzywa sumacyjna, a kolorem niebieskim histogram (procentowy udział klas ziarnowych). 


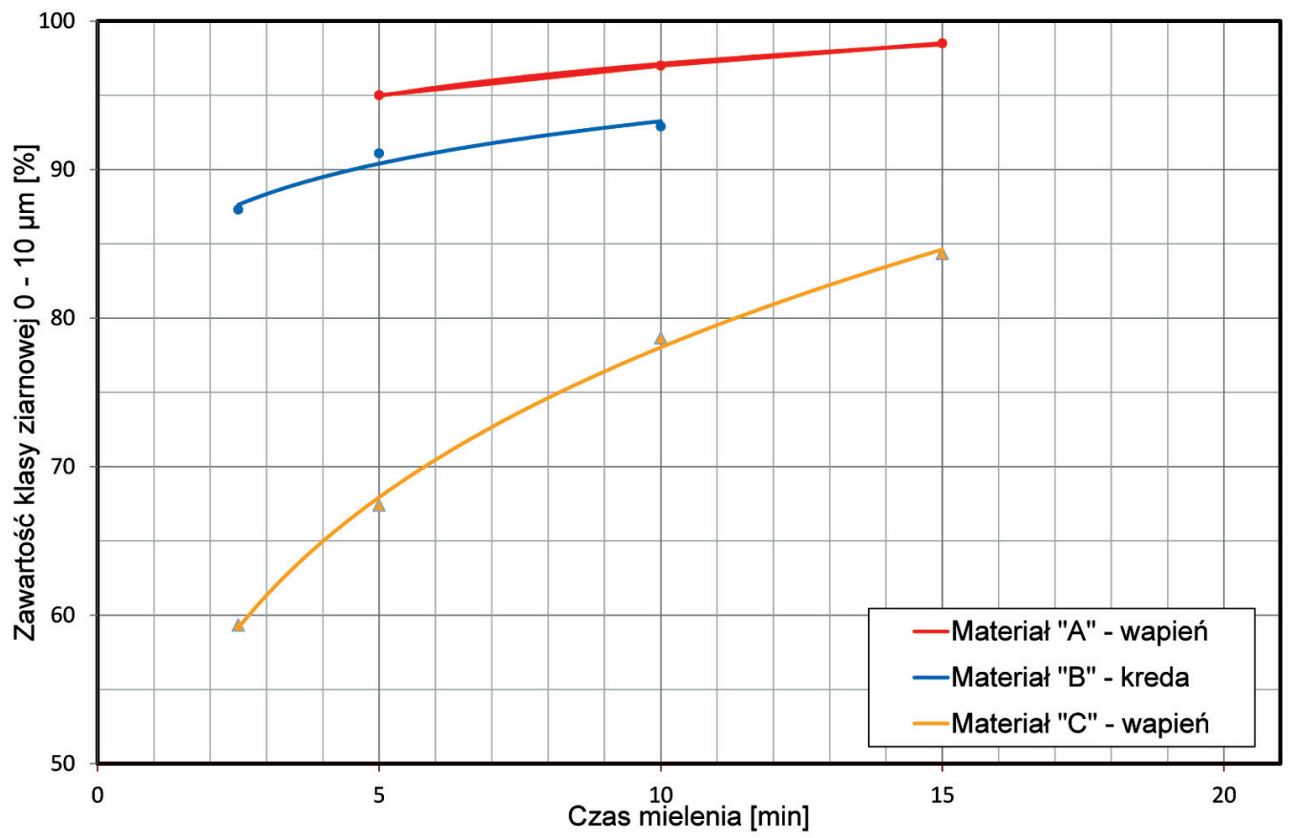

Rys. 2. Wpływ czasu mielenia wapieni i kredy na zawartości klasy ziarnowej 0-10 $\mu \mathrm{m}$

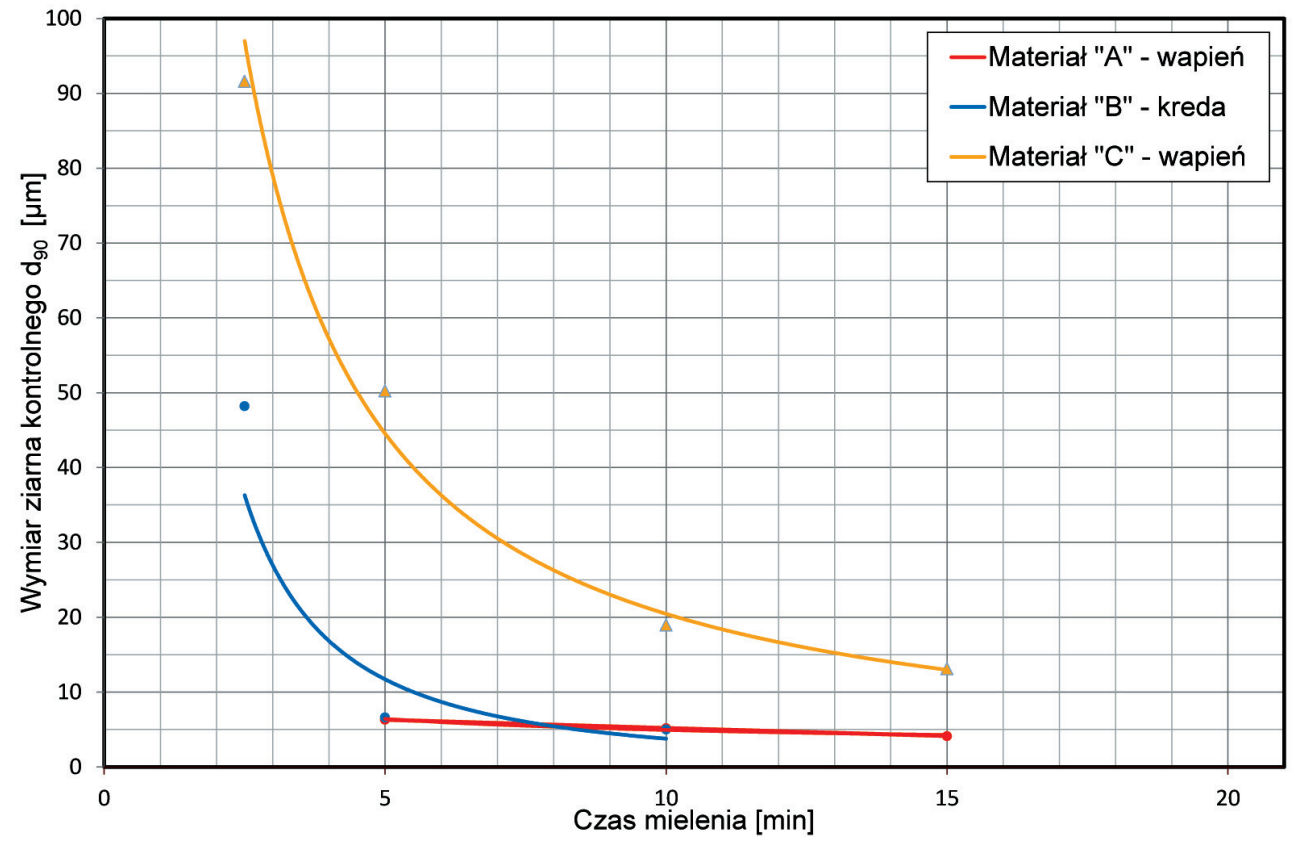

Rys. 3. Wpływ czasu mielenia wapieni i kredy na wymiar ziarna $d_{90}[\mu \mathrm{m}]$ 
Tabela 2

Wybrane parametry uziarnienia próbek poszczególnych materiałów (A, B, C) spełniających podstawowy wymóg technologiczny uziarnienia

\begin{tabular}{|c|c|c|c|c|c|}
\hline Próbka & $\begin{array}{c}\text { Czas } \\
\text { mielenia } \\
{[\mathrm{min}]}\end{array}$ & $\begin{array}{c}\text { Klasa 0-10 } \mu \mathrm{m} \\
{[\%]}\end{array}$ & $\begin{array}{c}\text { Klasa 0-20 } \mu \mathrm{m} \\
{[\%]}\end{array}$ & $\begin{array}{c}\text { Wymiar ziarna } \\
\mathrm{d}_{90}[\mu \mathrm{m}]\end{array}$ & $\begin{array}{c}\text { Wymiar ziarna } \\
\mathrm{d}_{97}[\mu \mathrm{m}]\end{array}$ \\
\hline MWAa-1 & 5 & 95,34 & 97,07 & 6,30 & 19,08 \\
\hline MWBa-1 & 2,5 & 87,30 & 87,92 & 48,21 & 121,31 \\
\hline MWCa-4 & 15 & 84,35 & 94,71 & 13,13 & 28,08 \\
\hline
\end{tabular}

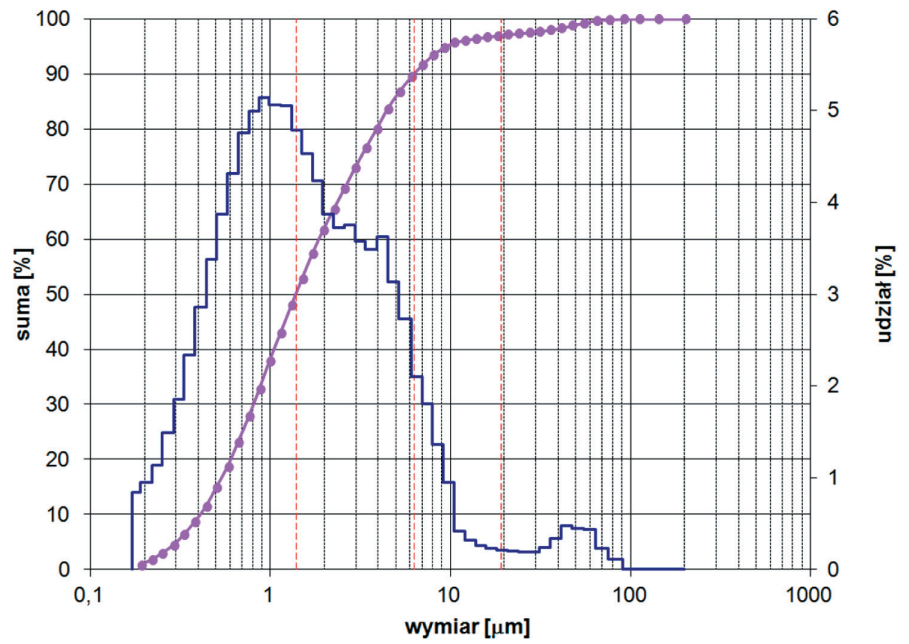

Rys. 4. Uziarnienie próbki materiału $\mathrm{A}$ - czas mielenia $t=5 \mathrm{~min}$

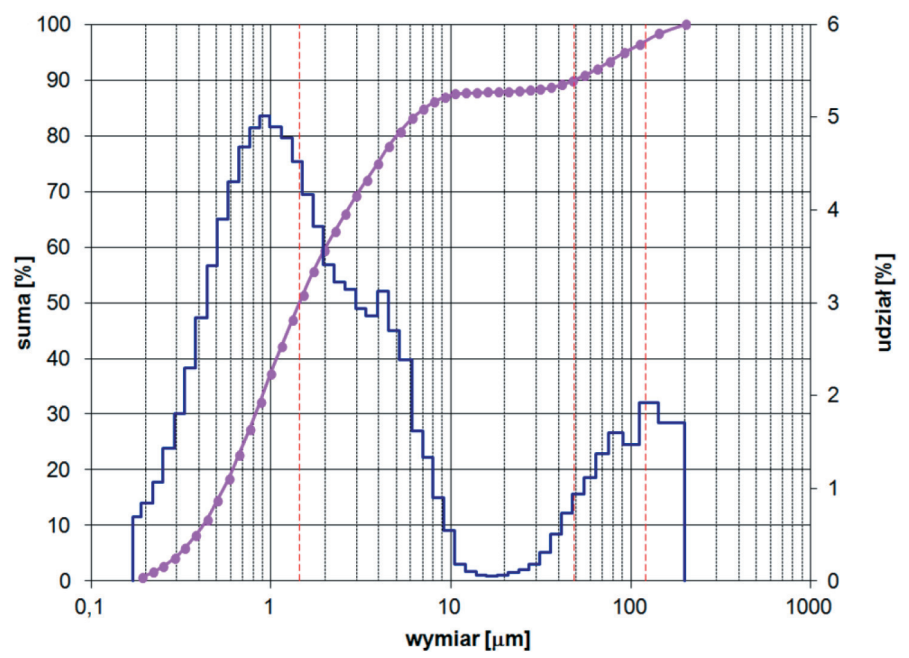

Rys. 5. Uziarnienie próbki materiału $\mathrm{B}$ - czas mielenia $t=2,5 \mathrm{~min}$ 


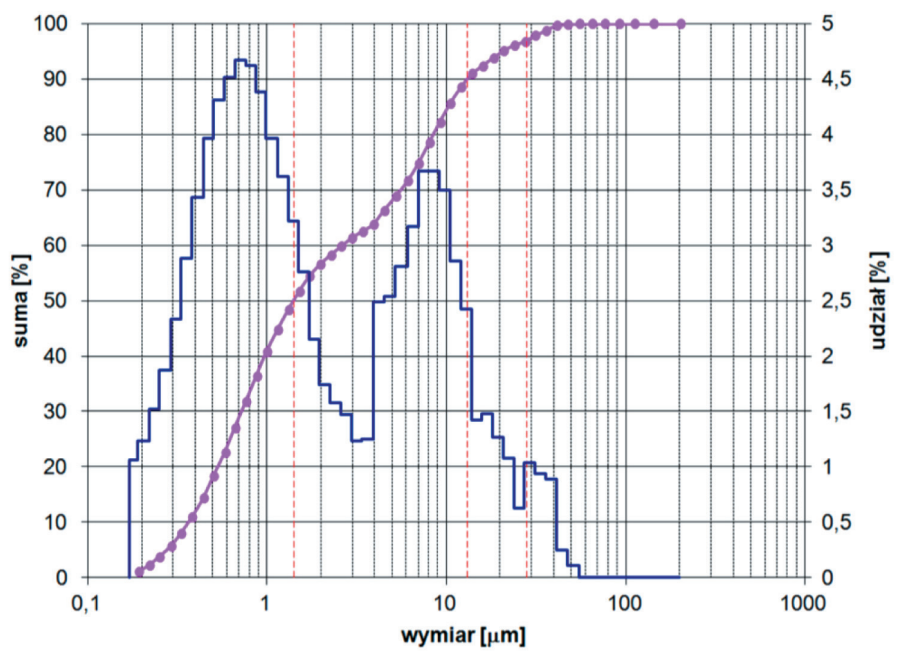

Rys. 6. Uziarnienie próbki materiału $\mathrm{C}$ - czas mielenia $t=15 \mathrm{~min}$

Próbki wszystkich materiałów zostały poddane granulacji bezciśnieniowej w granulatorze wibracyjnym (Sidor i in. 2014).

\section{Podsumowanie wyników badań i wnioski}

Użyte do badań materiały stanowiące nadawę do procesu mielenia różniły się znacznie uziarnieniem oraz pochodzeniem geologicznym. Materiał B miał uziarnienie 0-10 mm, materiał A - uziarnienie 0-4 mm, a materiał C - uziarnienie 0-6 mm.

We wszystkich przypadkach mielenia otrzymano wymagane uziarnienie próbek, czyli zawartość klasy 0-10 $\mu$ m powyżej 70\%. Najkorzystniejszy rezultat, 95,3\% zawartości klasy 0-10 $\mu \mathrm{m}$, uzyskano przy najdrobniejszym materiale (A) w czasie 5 min. Korzystny rezultat, $87,3 \%$ klasy $0-10 \mu \mathrm{m}$, otrzymano także przy znacznie „grubszym” materiale B, przy czym była to bardziej podatna na mielenie kreda. Materiał C wymagał znacznie dłuższego czasu mielenia, bo aż 15 minut. Wówczas uzyskano 84,3\% klasy 0-10 $\mu \mathrm{m}$, a wymaganą zawartość tej klasy (czyli 70\%) uzyskano już w czasie około 6 minut.

Proces mielenia wszystkich materiałów zachodził w zamkniętej komorze, bez aeracji (przewietrzania komory). Były to niekorzystne warunki, które nie występują w młynach przemysłowych o działaniu ciągłym. Brak aeracji spowodował znaczne spowolnienie procesu mielenia wskutek szkodliwych zjawisk aglomeracji i „coatingu”. Jednak pomimo tych niekorzystnych warunków proces mielenia wibracyjnego był bardzo intensywny. Doświadczenia z eksploatacji wibracyjnych młynów przemysłowych 
pracujących w sposób ciągły (Sidor 2002), a także młynów kulowych wskazują, że przy zastosowaniu aeracji komory szybkość mielenia znacznie się zwiększa, a w wielu przypadkach młynów nie można eksploatować bez wymuszonego przepływu powietrza lub innego gazu przez komorę.

Wyniki badań, pomimo ich sondażowego charakteru, potwierdzają możliwość bardzo drobnego mielenia wszystkich materiałów w młynie wibracyjnym, a zmielone w tych młynach materiały cechuje dobra podatność na granulację.

\section{Literatura}

Andres K., Haude F., 2010, Application of the Palla ${ }^{\mathrm{TM}}$ vibrating mill in ultra fine grinding circuits, Journal of the Southern African Institute of Mining and Metallurgy, vol. 110, s. 125-131.

Biń K., 2012, Najnowsze tendencje w zakresie badań nad procesami granulacji [materiały konferencyjne - niepublikowane].

Gock E., Corell J., 2006, Schwingmühlen, BHM Berg- und Hüttenmännische, Monatshefte, vol. 151, issue 6, s. 237-242. https://doi.org/10.1007/BF03165360.

Heffer P., Prud'homme M., 2014, Short-Term Fertilizer Outlook 2014-2015, IFA Strategic Forum, Marrakech, https:/www.fertilizer.org/images/Library_Downloads/2014_ifa_ marakech_outlook_summary.pdf [dostęp: 12.10.2021].

Heim A., 1998, Procesy mechaniczne $w$ inżynierii procesowej $i$ urzadzenia do ich realizacji, Wyd. Politechniki Łódzkiej, Łódź.

Malinowski P., Kołosowski M., Biskupski A., 2015, Zapewnienie jakości produkcji granulowanych nawozów mineralnych [materiały konferencyjne - niepublikowane].

Rule C.M., 2010, Stirred Milling - New Comminution Technology in the PGM Industry, Journal of the Southern African Institute of Mining and Metallurgy, vol. 111, s. $101-107$.

Sidor J., 2005, Badania, modele $i$ metody projektowania młynów wibracyjnych, Uczelniane Wydawnictwa Naukowo-Dydaktyczne AGH, Kraków.

Sidor J., 2011, Rozwój technologii wytwarzania proszków z zastosowaniem młynów wibracyjnych, Powder \& Bulk, Materiały Sypkie i Masowe, wyd. specjalne SyMas 2011, s. 19-23.

Sidor J., 2013, Nowe mtyny i układy mielenia $w$ technologii rozdrabniania rud $i$ surowców mineralnych, [w:] Klich A., Kozieł A. (red.), Innowacyjne i przyjazne dla środowiska techniki i technologie przeróbki surowców mineralnych: bezpieczeństwo - jakość efektywność: monografia, ITG KOMAG, Gliwice, s. 267-279.

Sidor J., Drzymała Z., 2002, Synteza konstrukcji przemysłowego mbyna wibracyjnego o niskiej częstotliwości drgań do mielenia tlenku chromu na sucho, Zeszyty Naukowe Politechniki Białostockiej - Budowa i Eksploatacja Maszyn, nr 9, s. 405-414. 
Sidor J., Wójcik M., Kordek J., 1997, Fine grinding of hard ceramic waste in the rotary-vibration mill, [w:] Waste materials in construction: putting theory into practice: proceedings of the International Conference on the Environmental and Technical Implications of Construction with Alternative Materials, WASCON'97, Houthem St. Gerlach, the Netherlands, 4-6 June 1997, Elsevier Science, s. 591-598.

Sidor J., Wyszomirski P., Feliks J., Tomach P., Mazur M., 2014, Sondażowe badania procesu bardzo drobnego mielenia i granulowania dolomitu $i$ wapienia oraz rozpoznanie złóż dolomitów i wapieni [prace zlecone AGH - niepublikowane].

Tamblyn R.J., 2009, Analysis of Energy Requirements in Stirred Media Mills, School of Chemical Engineering, The University of Birmingham [rozprawa doktorska].

Tomach P., 2017a, Model procesowy mtyna wibracyjnego uwzględniajacy wptyw elementu intensyfikującego proces mielenia, Przemysł Chemiczny, t. 96, nr 12, s. 2467-2470.

Tomach P., 2017b, Badania intensyfikacji procesu mielenia w młynie wibracyjnym, Przemysł Chemiczny, t. 96, nr 9, s. 1893-1897.

Tomach P., 2019, An attempt to increase technological capabilities of laboratory vibratory mills by changing the construction of chamber, [w:] Kotwica K. (red.), New trends in production engineering: monograph. Pt. 1, Engineering and technology, Sciendo, Warszawa, s. 195-205.

Tomach P., 2020, Wybrane wyniki badań bardzo drobnego mielenia $w$ laboratoryjnych młynach wibracyjnych, [w:] Krauze K. (red.), Mechanizacja, automatyzacja i robotyzacja w górnictwie 2020: monografia: praca zbiorowa, Wydawnictwa AGH, Kraków, s. $127-135$.

Warych J., 2004, Aparatura chemiczna i procesowa, Oficyna Wydawnicza Politechniki Warszawskiej, Warszawa. 